\title{
The Use of Mobile Personal Health Records for Hemoglobin A1c Regulation in Patients With Diabetes: Retrospective Observational Study
}

Dongjin Seo ${ }^{1 *}, \mathrm{BS}$; Yu Rang Park ${ }^{2 *}, \mathrm{PhD}$; Yura $\mathrm{Lee}^{3}, \mathrm{MD}, \mathrm{PhD}$; Ji Young Kim${ }^{4}, \mathrm{MS}$; Joong-Yeol Park ${ }^{5}, \mathrm{MD}, \mathrm{PhD}$; Jae-Ho Lee ${ }^{3,6}$, MD, PhD

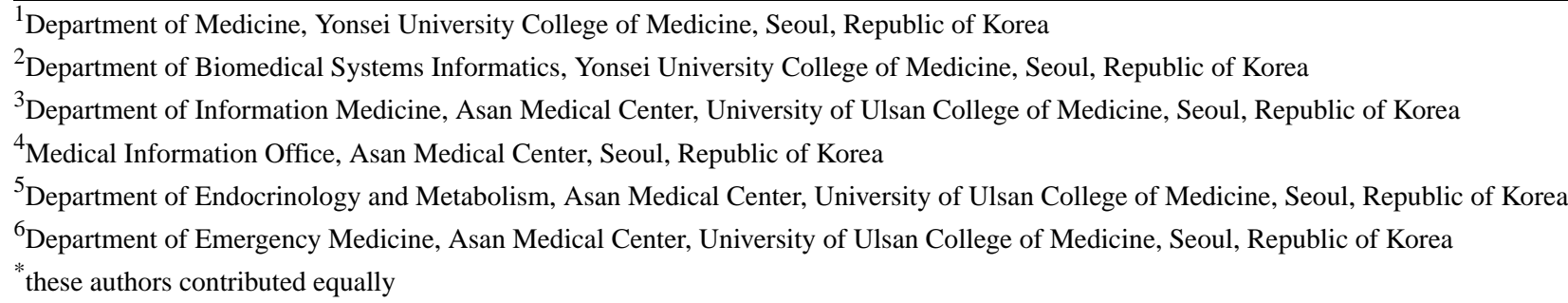

Corresponding Author:

Jae-Ho Lee, MD, PhD

Department of Information Medicine

Asan Medical Center, University of Ulsan College of Medicine

88 Olympic-ro 43-gil, Songpa-gu

Seoul, 05505

Republic of Korea

Phone: 82230103350

Email: rufiji@gmail.com

\section{Abstract}

Background: The effectiveness of personal health records (PHRs) in diabetes management has already been verified in several clinical trials; however, evidence of their effectiveness in real-world scenarios is also necessary. To provide solid real-world evidence, an analysis that is more accurate than the analyses solely based on patient-generated health data should be conducted.

Objective: This study aimed to conduct a more accurate analysis of the effectiveness of using PHRs within electronic medical records (EMRs). The results of this study will provide precise real-world evidence of PHRs as a feasible diabetes management tool.

Methods: We collected log data of the sugar function in the My Chart in My Hand version 2.0 (MCMH 2.0) app from Asan Medical Center (AMC), Seoul, Republic of Korea, between December 2015 and April 2018. The EMR data of MCMH 2.0 users from AMC were collected and integrated with the PHR data. We classified users according to whether they were continuous app users. We analyzed and compared their characteristics, patterns of hemoglobin $\mathrm{A}_{1 \mathrm{c}}\left(\mathrm{Hb}_{1 \mathrm{c}}\right)$ levels, and the proportion of successful $\mathrm{HbA}_{1 \mathrm{c}}$ control. The following confounders were adjusted for $\mathrm{HbA}_{1 \mathrm{c}}$ pattern analysis and $\mathrm{HbA}_{1 \mathrm{c}}$ regulation proportion comparison: age, sex, first $\mathrm{HbA}_{1 \mathrm{c}}$ measurement, diabetes complications severity index score, sugar function data generation weeks, $\mathrm{Hb}_{1 \mathrm{c}}$ measurement weeks before MCMH 2.0 start, and generated sugar function data count.

Results: The total number of MCMH 2.0 users was 64,932, with 7453 users having appropriate PHRs and diabetes criteria. The number of continuous and noncontinuous users was 133 and 7320, respectively. Compared with noncontinuous users, continuous users were younger $(P<.001)$ and had a higher male proportion $(P<.001)$. Furthermore, continuous users had more frequent $\mathrm{HbA}_{1 \mathrm{c}}$ measurements $(P=.007)$, shorter $\mathrm{HbA}_{1 \mathrm{c}}$ measurement days $(P=.04)$, and a shorter period between the first $\mathrm{HbA}_{1 \mathrm{c}}$ measurement and MCMH 2.0 start $(P<.001)$. Diabetes severity-related factors were not statistically significantly different between the two groups. Continuous users had a higher decrease in $\mathrm{HbA}_{1 \mathrm{c}}(P=.02)$ and a higher proportion of regulation of $\mathrm{HbA}$ lc levels to the target level $(P=.01)$. After adjusting the confounders, continuous users had more decline in $\mathrm{HbA}_{1 \mathrm{c}}$ levels than noncontinuous users $(P=.047)$. Of the users who had a first $\mathrm{HbA}_{1 \mathrm{c}}$ measurement higher than $6.5 \%$ (111 continuous users and 5716 noncontinuous 
users), continuous users had better regulation of $\mathrm{HbA}_{1 \mathrm{c}}$ levels with regard to the target level, 6.5\%, which was statistically significant $(P=.04)$.

Conclusions: By integrating and analyzing patient- and clinically generated data, we demonstrated that the continuous use of PHRs improved diabetes management outcomes. In addition, the $\mathrm{HbA}_{1 \mathrm{c}}$ reduction pattern was prominent in the PHR continuous user group. Although the continued use of PHRs has proven to be effective in managing diabetes, further evaluation of its effectiveness for various diseases and a study on PHR adherence are also required.

(J Med Internet Res 2020;22(6):e15372) doi: $\underline{10.2196 / 15372}$

\section{KEYWORDS}

personal health record; mobile health; electronic medical record; diabetes mellitus; glycated hemoglobin A

\section{Introduction}

\section{Background}

Diabetes mellitus is a global issue, and its contribution to numerous complications and increased mortality is well known. Moreover, diabetes prevalence is constantly growing, a trend that might continue until 2030 or longer [1,2]. According to the American Diabetes Association (ADA), diabetes care is mainly based on insulin delivery [3]. According to the Korean Diabetes Association (KDA), the target value of hemoglobin $\mathrm{A}_{1 \mathrm{c}}\left(\mathrm{HbA}_{1 \mathrm{c}}\right)$ is recommended to be $6.5 \%$ for patients with type 2 diabetes, and antihyperglycemic therapy is mainly considered in Korea. Metformin is considered to be the first-line therapy. However, these traditional drug therapies result in inevitable hypoglycemic events and body weight change. An unachieved glycemic target can only be solved by increasing drugs in mono, dual, or triple therapy [4]. Traditional methods are expensive, and this is becoming a national health care problem $[5,6]$. To overcome several limitations of traditional diabetes management, mobile health (mHealth) technology and personal health record (PHR) implementation have been suggested as innovative solutions.

In the diabetes management market, new treatments with new devices and apps are being introduced. Most functions of diabetes apps focus on maintaining a blood glucose diary. Some are also connected with blood glucose sensors and treatment devices. Among diabetes apps, OneTouch Reveal had the best validation [7]. This app is wirelessly connected to the OneTouch Verio Flex meter, making users self-monitor their blood glucose. Blood glucose data are delivered to health care professionals, and users receive text message feedback [8]. Technologies using automatic alarm systems have also been introduced. The Dexcom G6 Continuous Glucose Monitoring system effectively reduced hyperglycemia and also hypoglycemic events with the Urgent Low Soon automatic alert system [9]. Monitoring insulin delivery became possible with internet-based connections. NovoPen 6 and NovoPen Echo Plus are called smart insulin pens, which can monitor the insulin injection amount and provide both health providers and patients treatment accuracy $[10,11]$.

Previous studies have shown the health improvement of PHR users, thus suggesting that a digital health care system is feasible for improving health behavior and chronic conditions. According to a systematic review, users experienced a positive effect on their health-related behavior and clinical results when using health apps on their mobile devices [12]. Another systematic review in South Korea showed that mHealth interventions were effective in improving self-management behaviors, biomarkers, or patient-reported outcome measures [13]. However, the positive effect of mHealth and PHR interventions is not always ensured.

In diabetes care, PHR and mHealth interventions are expected to be effective treatments. WellDoc, a remote blood glucose monitoring system, was effective in lowering $\mathrm{HbA}_{1 \mathrm{c}}$ levels, thereby improving clinical, behavioral, and diabetes knowledge outcomes [14]. A phone-based treatment and behavioral coaching intervention also improved $\mathrm{HbA}_{1 \mathrm{c}}$ levels [15]. A similar improvement in $\mathrm{HbA}_{1 \mathrm{c}}$ control for type 2 diabetes was seen with another mobile-based intervention [16]. The addition of a tailored mobile coaching system for patients with diabetes showed reduced $\mathrm{HbA}_{1 \mathrm{c}}$ levels and improved diabetes self-management; the results were reproducible and durable [17].

Along with the expectations of the clinical implications of PHRs, some concerns and slightly controversial results have been reported. Despite its advantages, studies have reported the barriers in PHR implementation. Patients are concerned about the security of their health information. Health care providers are concerned about patients altering their own PHR information. Other issues are that there is no practical difference in health outcomes, the use of stand-alone PHRs with electronic medical records (EMRs) and electronic health records, and a low health care literacy rate, which can diminish the benefits of PHRs [18]. Moreover, the barriers associated with patients' age, sex, socioeconomic status, education level, internet and computer access, and health have been reviewed [19]. Contrasting results of the relation between PHR use and diabetes management have been reported. A study using a regression model claimed that there was no association between the increasing number of days of PHR use and better diabetes quality measure profiles [20].

\section{Objectives}

In this study, we used a 4-year mobile PHR (mPHR) log and users' EMR data to analyze the effects of diabetes management on the continuous use of the PHR system distributed by a tertiary hospital in South Korea. A study with the earlier version of the mPHR app was conducted to verify characteristics of continuous users [21], and patient-generated health data (PGHD) of continuous users had a higher proportion of a chronic disease diagnosis, such as diabetes, than noncontinuous users [22]. With 
the new version, we will verify its effect in glycemic control on patients with diabetes. To the best of our knowledge, this is the first study to verify the effectiveness of disease management by integrating a long-term mPHR log and EMR data.

\section{Methods}

Data and Mobile Personal Health Record Description

We collected log data from an mPHR app called My Chart in My Hand (MCMH) and their EMR data at the Asan Medical Center (AMC), which is the largest general hospital in South Korea. Launched in January 2011, MCMH is the first mPHR in South Korea; it enables patients to view and manage their own health records [21]. We used the MCMH version $1.0 \mathrm{log}$ to identify patterns of continuous generation of PGHD in specific populations [22]. This study performed a diabetes management analysis using the MCMH version $2.0 \mathrm{log}$ and EMR data. For patients with diabetes, MCMH version 2.0 provides sugar, diabetes calendar, insulintreatment, food intake, and exercise input functions. Among these functions, we only used the log data of the sugar and diabetes calendar function; the remaining functions had very few records. The items in Figure 1 show the details of the sugar function. Users enter the date, time, situation, and result of their blood glucose measurement in these PGHD functions.

We also gathered demographic and medical record information of patients, such as age, sex, residence, and health information, including hospital visits, $\mathrm{HbA}_{1 \mathrm{c}}$ level, diagnosis, and medication data, using our clinical research data warehouse.

Figure 1. Screenshots of My Chart in My Hand version 2.0. Inputting data in the sugar function follows from the home page to Enter Blood Glucose.

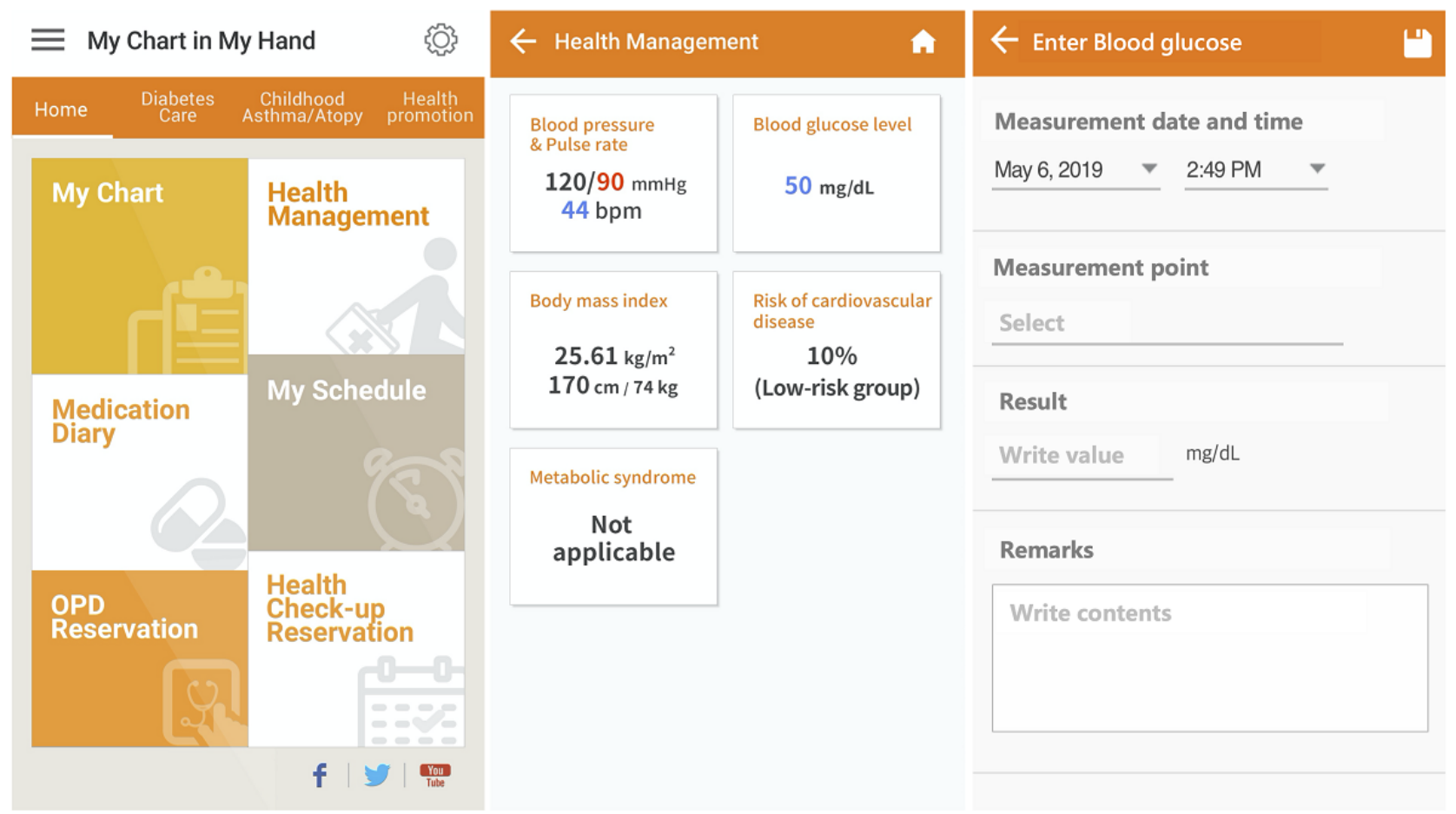

\section{Study Design}

MCMH version 2.0 replaced MCMH version 1.0 on December 31,2015 , but some patients had already created their accounts in December 2015 before the replacement. For each user, the records generated in $\mathrm{MCMH}$ version 2.0 functions were analyzed, but only records generated after account creation were used.

The user log of the sugar function contained user access ID and time stamps of data input. We gathered the $\mathrm{HbA}_{1 \mathrm{c}}$ measurement results of MCMH version 2.0 users from January 2014 to November 2018.

For user selection, we used the criteria of diabetes for diagnosis. First, the criterion of Glasheen et al [23] was adopted: a user should have one or more International Classification of Diseases 10th Revision (ICD-10) diabetes codes in the diagnosis record, which are E08, E09, E10, E11, and E13. Second, the $\mathrm{HbA}_{1 \mathrm{c}}$ cutoff value of $6.5 \%$ for diagnosing diabetes was used [24]. For the complication classification and diabetes complications severity index (DCSI) scoring, the selected complication fields from the diagnosis record were retinopathy, nephropathy, neuropathy, cerebrovascular, cardiovascular, peripheral vascular disease, and metabolic complications. DCSI scoring used the criteria of the study by Glasheen et al [23]. However, urine laboratory data were not included in DCSI scoring because of its unavailability. Above all, we classified all diseases according to ICD-10.

The criterion for whether a user was a continuous user was adopted from the PGHD pattern analysis study of MCMH version 1.0: a user entering data in the sugar function at least once per week and doing so for at least four weeks (28 days) [22].

We analyzed the pattern of $\mathrm{HbA}_{1 \mathrm{c}}$ levels with the trend line slope of $\mathrm{HbA}_{1 \mathrm{c}}$ levels. The fluctuation of $\mathrm{HbA}_{1 \mathrm{c}}$ levels was 
compared with the $r$-squared value of the trend line and the standard deviation of the patient's $\mathrm{HbA}_{1 \mathrm{c}}$ level.

In this study, the trend line slope considerably depended on the measurement days between the first and last $\mathrm{HbA}_{1 \mathrm{c}}$ measurement. Therefore, we created a patient filter called appropriate $\mathrm{HbA}_{\text {lc }}$ measurement. This criterion excluded patients with short periods between measures because a short period will lead to an exaggeratedly steep slope, which is inappropriate for the analysis. The criterion for an appropriate $\mathrm{HbA}_{1 \mathrm{c}}$ measurement is patients should have at least two $\mathrm{HbA}_{1 \mathrm{c}}$ measurements and the period between the first and last $\mathrm{HbA}_{1 \mathrm{c}}$ measurement should be over 100 days. To normalize the effect of measurement days between the first and last $\mathrm{HbA}_{1 \mathrm{c}}$ measurement, we defined a variable called decline. Decline is defined as a trend line slope times the period (in days) divided by 100 . This normalization is represented in the equation in Multimedia Appendix 1.

This study was approved by the Institutional Review Board (IRB) of the AMC (IRB number: 2018-0321). The need for informed consent was waived by the ethics committee because this study utilized routinely collected log data that were anonymously managed at all stages, including during data cleaning and statistical analyses.

\section{Study Participants}

Figure 2 shows the patient selection flow in this study. Among 64,932 users who downloaded and created an MCMH version 2.0 account, we first excluded 51,433 users with inappropriate $\mathrm{HbA}_{1 \mathrm{c}}$ measurements. We considered 13,499 users with the appropriate $\mathrm{HbA}_{1 \mathrm{c}}$ measurements, excluded 6046 users without diabetes, and selected 7453 users with diabetes.

Figure 2. Patient inclusion and exclusion criteria (white boxes) and flow through the study. The gray box shows user hemoglobin $A_{1 c}\left(H b A_{1 c}\right)$ analyses. Criteria for appropriate $\mathrm{HbA}_{1 \mathrm{c}}$ measurement: two or more $\mathrm{HbA}_{1 \mathrm{c}}$ measurements, duration of the first and last measurement over 100 days, and creating My Chart in My Hand version 2.0 account during $\mathrm{HbA}_{1 \mathrm{c}}$ measurement. Criteria for diabetes diagnosis: having International Classification of Diseases 10th Revision code E08, E09, E10, E11, or E13 or first $\mathrm{HbA}_{1 \mathrm{c}}$ measurement $\geq 6.5 \%$. Criteria for continuous use of sugar function: patient-generated health data entered in the sugar function at least once per week and used for at least 28 days. ${ }^{a} \mathrm{HbA}_{1 \mathrm{c}}$ : hemoglobin $\mathrm{A}_{1 \mathrm{c}}$; ${ }^{\mathrm{b}} \mathrm{MCMH}$ : My Chart in My Hand.

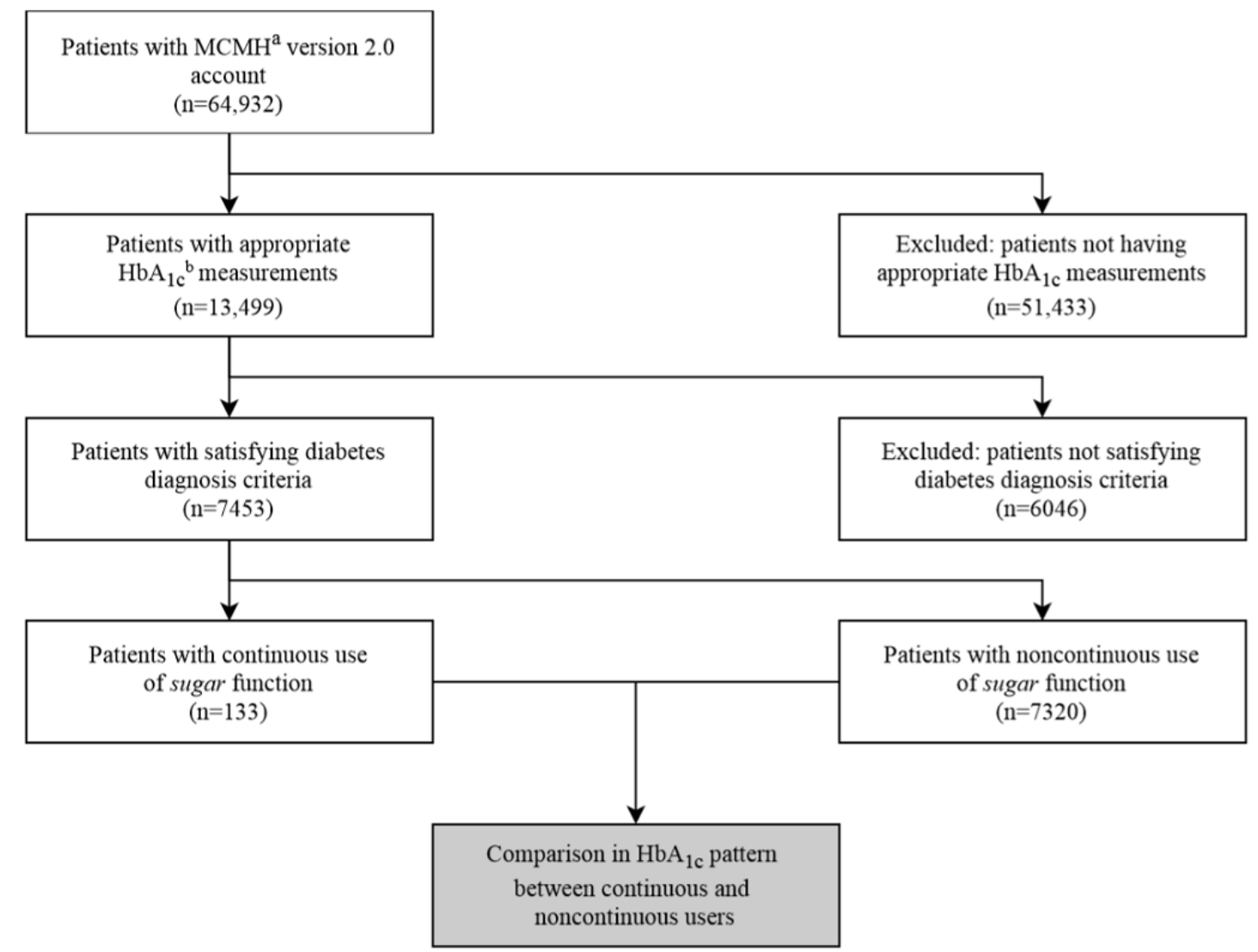

\section{Data Analysis}

We first compared the general characteristics of continuous $(n=133)$ and noncontinuous users $(n=7320)$. The following characteristics were compared: age, gender proportion, sugar and diabetes calendar function use pattern, $\mathrm{HbA}_{1 \mathrm{c}}$ measurement pattern, $\mathrm{HbA}_{1 \mathrm{c}}$ value, DCSI score, and complication proportion. A Student $t$ test was conducted for the comparison of age, the number of $\mathrm{HbA}_{1 \mathrm{c}}$ measurements, measurement days, and measurement days before MCMH version 2.0 start. A Wilcoxon rank-sum test was used for individual sugar and diabetes calendar function data generation, $\mathrm{HbA}_{1 \mathrm{c}}$ measure frequency, first $\mathrm{HbA}_{1 \mathrm{c}}$ measurement, and DCSI score comparison. The median test was used for the individual sugar and diabetescalendar function data generation comparison. The $\mathrm{Z}$ test was conducted for sugar and diabetes function generation user proportion, first $\mathrm{HbA}_{1 \mathrm{c}}$ measurement over $6.5 \%$ proportion, 
and complications proportion comparisons. For gender proportion comparison and DCSI score distribution, a chi-square test was used.

Next, comparative analyses of $\mathrm{HbA}_{1 \mathrm{c}}$ decline, $r$-squared value, and standard deviation between continuous and noncontinuous users were performed. We used the Shapiro-Wilk test and D'Agostino K-squared test to determine if these data followed a normal distribution. $\mathrm{HbA}_{1 \mathrm{c}}$ decline, $r$-squared value, and standard deviation were compared using the Wilcoxon rank-sum test. For confounder adjustment, we used an analysis of covariance (ANCOVA) with some variables: continuous use, age, sex, first $\mathrm{HbA}_{1 \mathrm{c}}$ measurement, DCSI, sugar function data generation weeks, $\mathrm{HbA}_{1 \mathrm{c}}$ measurement in weeks before $\mathrm{MCMH}$ version 2.0 start, and sugar function data generation count.

Finally, the $\mathrm{Z}$ test was conducted for comparing the proportions of 4 groups between continuous and noncontinuous users. The 4 groups were divided by whether the first $\mathrm{HbA}_{1 \mathrm{c}}$ measurement was higher or lower than $6.5 \%$ and whether the last $\mathrm{HbA}_{1 \mathrm{c}}$ measurement was higher or lower than $6.5 \%$. For confounder adjustment, multivariable logistic regression was used for users with the first $\mathrm{HbA}_{1 \mathrm{c}}$ measurement over $6.5 \%$. The same variables, as used in ANCOVA, were used for logistic regression. Data analyses were conducted using Python 3.6.7, with Jupyter Notebook.

\section{Results}

\section{Overall Characteristics}

Within 29 months of operation of MCMH version 2.0, 64,932 users created an account and logged in at least once. Among these users, 7453 users were selected on the basis of the inclusion criteria of this study. Approximately $1.78 \%(133 / 7453)$ of these users were continuous users, and 98.22\% (7320/7453) were noncontinuous users. Continuous and noncontinuous users had no statistically significant difference in the number of $\mathrm{HbA}_{1 \mathrm{c}}$ measurements and the period between the first and last $\mathrm{HbA}_{1 \mathrm{c}}$ measurements.
Table 1 summarizes the results of a basic characteristic analysis between continuous and noncontinuous users. In Table 1, measure frequency refers to the number of measurements per day, measurement days refers to days between the first and last $\mathrm{HbA}_{1 \mathrm{c}}$ measurement, and measurement days before MCMH version 2.0 start refers to days between the first $\mathrm{HbA}_{1 \mathrm{c}}$ measurement and MCMH version 2.0 account generation period. Compared with noncontinuous users, continuous users were younger (mean 53.59, SD 9.89 years vs mean 57.58, SD 11.95 years, respectively) and had a higher male proportion (110/133, $82.7 \%$ vs $4859 / 7320,66.38 \%$, respectively), which was statistically significant (both $P<.001$ ). The number of $\mathrm{HbA}_{1 \mathrm{c}}$ measurements was not significantly different. The frequency and period between the first and last measurements exhibited a significant difference between continuous and noncontinuous users ( $P=.007$ and $P=.04$, respectively). The proportion of patients with the first $\mathrm{HbA}_{1 \mathrm{c}}$ measurement below $6.5 \%$ had no significant difference $(P=.14)$, but continuous users had a higher first $\mathrm{HbA}_{1 \mathrm{c}}$ measurement, and this was statistically significant $(P=.01)$. Furthermore, among continuous users, there were a higher proportion of users who generated data in the sugar function and diabetes calendar function (both $P<.001$ ). Continuous users also entered more sugar and diabetes calendar data (both $P<.001$ ). The DCSI score had no significant difference $(P=.99)$. The proportion of complications, defined by the DCSI criteria, also showed no significant difference between continuous and noncontinuous users. Although the difference was statistically insignificant, retinopathy and cardiovascular complications had a proportional difference.

The DCSI score proportion of continuous and noncontinuous users had no significant difference in the chi-square test. This can be found in Multimedia Appendix 2. Among the 14 DCSI scores, those with zero proportion in both patient groups (scores 10, 12, and 13) were excluded in the analysis using the chi-square test, because calculation with the chi-square test is only possible when each score does not have zero proportion in any group. 
Table 1. General characteristics of continuous and noncontinuous users.

\begin{tabular}{|c|c|c|c|c|}
\hline \multirow[t]{2}{*}{ Variables } & \multicolumn{2}{|l|}{ Users } & \multirow[t]{2}{*}{ Total $(\mathrm{N}=7453)$} & \multirow[t]{2}{*}{$P$ value $^{\mathrm{a}}$} \\
\hline & Continuous $(n=133)$ & Noncontinuous $(\mathrm{n}=7320)$ & & \\
\hline Age (years), mean (SD) & $53.59(9.89)$ & $57.58(11.95)$ & $57.51(11.92)$ & $<.001$ \\
\hline $\operatorname{Sex}, \mathbf{n}(\%)$ & & & & $<.001$ \\
\hline Male & $110(82.7)$ & $4859(66.37)$ & $4969(66.67)$ & \\
\hline Female & $23(17.3)$ & $2461(33.62)$ & $2484(33.33)$ & \\
\hline \multicolumn{5}{|l|}{ Sugar function } \\
\hline Data generated by users, n (\%) & $133(100.0)$ & $289(3.95)$ & $422(5.66)$ & $<.001$ \\
\hline Total data generated, $\mathrm{n}$ & 22,350 & 1345 & 23,695 & $-b$ \\
\hline Individually generated data & & & & $<.001$ \\
\hline Median (IQR) & $97(43-186)$ & $0(0-0)$ & $0(0-0)$ & \\
\hline \multicolumn{5}{|l|}{ Diabetes calendar function } \\
\hline Data generated by users, n (\%) & $133(100.0)$ & $297(4.06)$ & $430(5.77)$ & $<.001$ \\
\hline Total data generated, $\mathrm{n}$ & 16,407 & 1453 & 17,860 & - \\
\hline Individually generated data & & & & $<.001$ \\
\hline Mean (SD) & $123.4(143.3)$ & $0.2(4.0)$ & $2.4(25.4)$ & \\
\hline Median (IQR) & $67(35-145)$ & $0(0-0)$ & $0(0-0)$ & \\
\hline \multicolumn{5}{|l|}{$\mathrm{HbA}_{1 \mathrm{c}}{ }^{\mathrm{c}}$, mean (SD) } \\
\hline Number of measurements & $12.44(6.90)$ & $11.90(6.82)$ & $11.92(6.82)$ & .38 \\
\hline Measurement days & $1254(461)$ & $1336(445)$ & $1335(446)$ & .04 \\
\hline Measurement days before $\mathrm{MCMH}^{\mathrm{d}}$ version 2.0 start & $546(348)$ & $712(377)$ & $710(377)$ & $<.001$ \\
\hline First $\mathrm{HbA}_{1 \mathrm{c}}$ measurement $\geq 6.5 \%, \mathrm{n}(\%)$ & $111(83.4)$ & $5716(78.09)$ & $5827(78.18)$ & .14 \\
\hline First $\mathrm{HbA}_{1 \mathrm{c}}$ measurement, mean (SD) & $7.86(1.78)$ & $7.51(1.62)$ & $7.51(1.62)$ & .01 \\
\hline $\mathrm{DCSI}^{\mathrm{e}}$, mean $(\mathrm{SD})$ & $1.17(1.65)$ & $1.15(1.64)$ & $1.15(1.64)$ & .99 \\
\hline \multicolumn{5}{|l|}{ Complications, n (\%) } \\
\hline Retinopathy or ophthalmic & $31(23.3)$ & $1516(20.71)$ & $1547(20.75)$ & .46 \\
\hline Nephropathy & $13(9.8)$ & $765(10.45)$ & $778(10.44)$ & .80 \\
\hline Neuropathy & $23(17.3)$ & $1267(17.31)$ & $1290(17.31)$ & $>.99$ \\
\hline Cerebrovascular & $20(15.0)$ & $950(13.00)$ & $970(13.01)$ & .48 \\
\hline Cardiovascular & $16(12.0)$ & $1366(18.7)$ & $1382(18.54)$ & .05 \\
\hline Peripheral vascular disease & $1(0.8)$ & $59(0.8)$ & $60(0.81)$ & .94 \\
\hline Metabolic complications & $1(0.8)$ & $37(0.5)$ & $38(0.51)$ & .69 \\
\hline
\end{tabular}

${ }^{\mathrm{a}}$ Chi-square test or Z test (for categorical variables); Student $t$ test or Wilcoxon rank-sum test (for continuous variables).

${ }^{\mathrm{b}}$ Statistical comparison was not conducted in total generated data of sugar and diabetes calendar function.

${ }^{\mathrm{c}} \mathrm{HbA}_{1 \mathrm{c}}$ : hemoglobin $\mathrm{A}_{1 \mathrm{c}}$.

${ }^{\mathrm{d}} \mathrm{MCMH}$ : My Chart in My Hand.

${ }^{\mathrm{e}}$ DCSI: diabetes complications severity index. 


\section{Hemoglobin A Ac $_{1 \mathrm{c}}$ Pattern Analysis According to Continuous Use}

Figure 3 shows the trend of the $\mathrm{HbA}_{1 \mathrm{c}}$ pattern for continuous and noncontinuous users. The $\mathrm{HbA}_{1 \mathrm{c}}$ decline of continuous and noncontinuous users was also compared. The $\mathrm{HbA}_{1 \mathrm{c}}$ decline (mean -0.00533, SD 0.0144) in continuous users was significantly steeper than that of noncontinuous users (mean -0.00278 , SD 0.0137; $P=.02$ ). The SD of continuous users (mean 0.832 , SD 0.574) was significantly higher than that of noncontinuous users (mean 0.719 , SD $0.541 ; P=.005$ ). However, the $r$-squared value had no statistically significant difference between continuous and noncontinuous users $(P=.40)$.

When adjusting confounders that can contribute to the decline, continuous use had a statistically significant effect $(P=.047)$ on making decline steeper, as seen in Table 2. In addition, age, first $\mathrm{HbA}_{1 \mathrm{c}}$ measurement, DCSI, weeks of sugar function data generation, and $\mathrm{HbA}_{1 \mathrm{c}}$ measurement in weeks before $\mathrm{MCMH}$ version 2.0 start showed statistically significant effects $(P=.004$; $P<.001 ; P=.01 ; P=.003 ; P<.001$, respectively).

Figure 3. Hemoglobin $\mathrm{A}_{1 \mathrm{c}}\left(\mathrm{HbA}_{1 \mathrm{c}}\right.$ ) patterns (decline, r-squared value, and $\mathrm{SD}$ ) of continuous and noncontinuous users. The $\mathrm{x}$-axis is the percentage of days past from the first $\mathrm{HbA}_{1 \mathrm{c}}$ measurement compared with the period between the first and last $\mathrm{HbA}_{1 \mathrm{c}}$ measurements. The dashed lines are the $\mathrm{HbA}_{1 \mathrm{c}}$ decline of each patient. The slope and y-axis intercept of the continuous lines indicates the mean of slope and y-axis of patients, respectively.
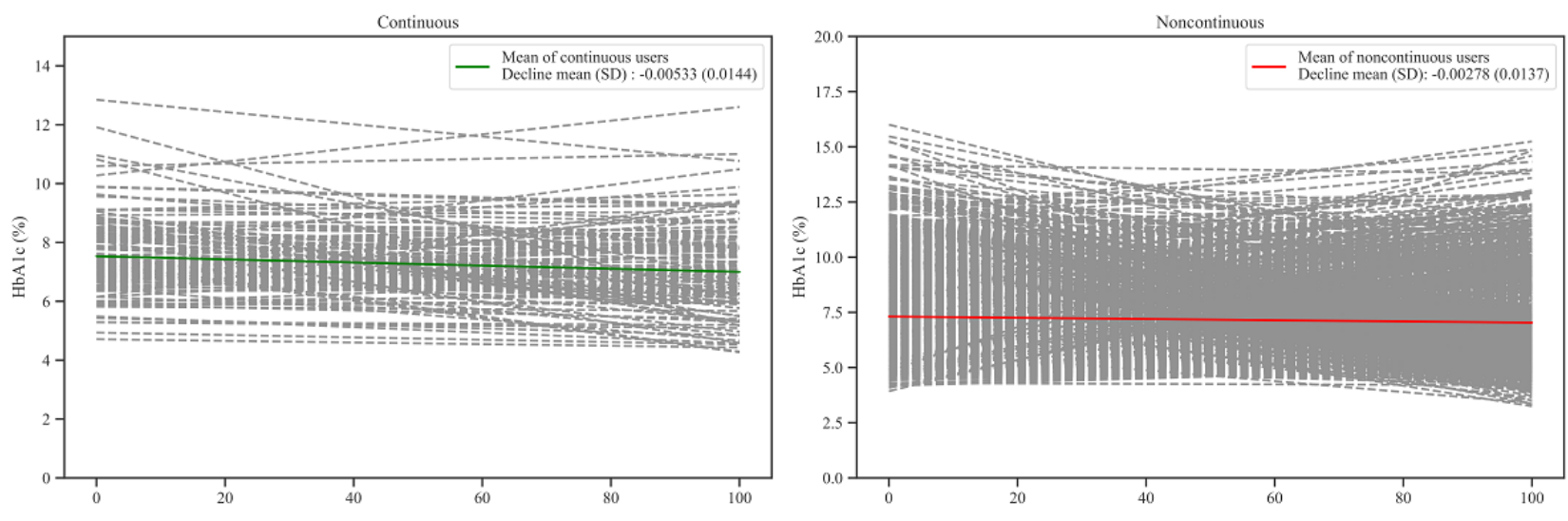

Table 2. Results of adjusting confounders with the analysis of covariance in decline comparison.

\begin{tabular}{|c|c|c|}
\hline Variables & $F$ test $(d f=1)$ & $P$ value \\
\hline Continuous users & 3.94 & .047 \\
\hline Age (years) & 8.07 & .004 \\
\hline Sex & 0.17 & .68 \\
\hline First $\mathrm{HbA}_{1 \mathrm{c}}{ }^{\mathrm{a}}$ measurement & 3054.90 & $<.001$ \\
\hline $\mathrm{DCSI}^{\mathrm{b}}$ & 6.45 & .01 \\
\hline Sugar function data generation (weeks) & 8.68 & .003 \\
\hline $\mathrm{HbA}_{1 \mathrm{c}}$ measurement weeks before MCMH version 2.0 start & 154.25 & $<.001$ \\
\hline Generated sugar function data count & 0.03 & .86 \\
\hline
\end{tabular}

${ }^{\mathrm{a}} \mathrm{HbA}_{1 \mathrm{c}}$ : hemoglobin $\mathrm{A}_{1 \mathrm{c}}$.

${ }^{\mathrm{b}}$ DCSI: diabetes complications severity index.

\section{Comparison of Hemoglobin $A_{1 c}$ Regulation With Target Level in Continuous Use}

Table 3 lists the proportion with regard to $\mathrm{HbA}_{1 \mathrm{c}}$ patterns. The proportion of users with the first $\mathrm{HbA}_{1 \mathrm{c}}$ measurement higher than $6.5 \%$ and the last $\mathrm{HbA}_{1 \mathrm{c}}$ measurement lower than $6.5 \%$ had a statistical difference $(P=.01)$. Among users with the first $\mathrm{HbA}_{1 \mathrm{c}}$ measurement lower than $6.5 \%$, the proportion of patients with the last $\mathrm{HbA}_{1 \mathrm{c}}$ measurement lower than $6.5 \%$ and the last $\mathrm{HbA}_{1 \mathrm{c}}$ measurement higher than $6.5 \%$ had no significant difference $(P=.34$ and $P=.29$, respectively). No significant difference was found between proportions of patients with the first $\mathrm{HbA}_{1 \mathrm{c}}$ measurement of $6.5 \%$ or higher and the last $\mathrm{HbA}_{1 \mathrm{c}}$ measurement higher than $6.5 \%(P=.41)$.

Similar to the decline analysis, the result of confounder adjustment by logistic regression for users with a high first $\mathrm{HbA}_{1 \mathrm{c}}$ measurement is summarized in Table 4. The continuous use of MCMH version 2.0 had a statistically significant effect in helping users move from an $\mathrm{HbA}_{1 \mathrm{c}}$ measurement above $6.5 \%$ to an $\mathrm{HbA}_{1 \mathrm{c}}$ measurement below $6.5 \%(P=.04)$. In addition, age, first $\mathrm{HbA}_{1 \mathrm{c}}$ measurement, and $\mathrm{HbA}_{1 \mathrm{c}}$ measurement in weeks 
before MCMH version 2.0 start showed statistically significant $\quad$ effects (all: $P<.001$ ).

Table 3. Pre- and post-hemoglobin $A_{1 c}$ management comparison by continuous use.

\begin{tabular}{|c|c|c|c|}
\hline \multirow[t]{2}{*}{$\mathrm{HbA}_{1 \mathrm{c}}{ }^{\mathrm{a}}$ pattern } & \multicolumn{2}{|l|}{ Users } & \multirow[t]{2}{*}{$P$ value } \\
\hline & Continuous $(\mathrm{n}=133)$ & Noncontinuous $(\mathrm{n}=7320)$ & \\
\hline \multicolumn{4}{|c|}{ First measurement $<6.5 \%$} \\
\hline \multicolumn{4}{|l|}{ Last measurement } \\
\hline$<6.5 \%, \mathrm{n}(\%)$ & $15(11.3)$ & $1040(14.21)$ & .34 \\
\hline$\geq 6.5 \%, \mathrm{n}(\%)$ & $7(5.3)$ & $564(7.70)$ & .29 \\
\hline \multicolumn{4}{|c|}{ First measurement $\geq 6.5 \%$} \\
\hline \multicolumn{4}{|l|}{ Last measurement } \\
\hline$<6.5 \%, \mathrm{n}(\%)$ & $38(28.6)$ & $564(7.70)$ & .01 \\
\hline$\geq 6.5 \%, \mathrm{n}(\%)$ & $73(54.9)$ & $4278(58.44)$ & .41 \\
\hline
\end{tabular}

${ }^{\mathrm{a}} \mathrm{HbA}_{1 \mathrm{c}}$ : hemoglobin $\mathrm{A}_{1 \mathrm{c}}$.

Table 4. The result of logistic regression against users with a high first hemoglobin $\mathrm{A}_{1 \mathrm{c}}$ measurement $(\mathrm{n}=111$ continuous and $\mathrm{n}=5716$ noncontinuous users).

\begin{tabular}{|c|c|c|}
\hline Variables & Coefficient & $P$ value \\
\hline Constant & 1.640 & $<.001$ \\
\hline Continuous & 0.618 & .04 \\
\hline Age (years) & -0.010 & $<.001$ \\
\hline Sex & -0.085 & .20 \\
\hline First $\mathrm{HbA}_{1 \mathrm{c}}{ }^{\mathrm{a}}$ measurement & -0.171 & $<.001$ \\
\hline DCSI $^{\mathrm{b}}$ & -0.041 & .05 \\
\hline Sugar function data generation (weeks) & -0.004 & .23 \\
\hline $\mathrm{HbA}_{1 \mathrm{c}}$ measurement in weeks before $\mathrm{MCMH}^{\mathrm{c}}$ version 2.0 use start & -0.008 & $<.001$ \\
\hline Generated sugar function data count & -0.001 & .52 \\
\hline
\end{tabular}

${ }^{\mathrm{a}} \mathrm{HbA}_{1 \mathrm{c}}$ : hemoglobin $\mathrm{A}_{1 \mathrm{c}}$.

${ }^{b}$ DCSI: diabetes complications severity index.

${ }^{\mathrm{c}} \mathrm{MCMH}$ : My Chart in My Hand.

\section{Discussion}

\section{Principal Findings}

For the following reasons, this study supports the use of mPHRs as an effective platform for diabetes management by integrating patient-generated health and clinical data from PHRs and EMRs, respectively. First, analyzing the characteristics of continuous users of MCMH version 2.0, male patients with a high $\mathrm{HbA}_{1 \mathrm{c}}$ level seemed to use MCMH version 2.0 more continuously. Second, the continuous use of PHRs resulted in a higher decrease of $\mathrm{HbA}_{1 \mathrm{c}}$ levels and enhanced the regulation of high $\mathrm{HbA}_{1 \mathrm{c}}$ levels of patients to the target range. Therefore, male users with high $\mathrm{HbA}_{1 \mathrm{c}}$ levels had a higher decrease in $\mathrm{HbA}_{1 \mathrm{c}}$ levels and improved $\mathrm{HbA}_{1 \mathrm{c}}$ regulation to the target level. By analyzing the characteristics of continuous users and their $\mathrm{HbA}_{1 \mathrm{c}}$ patterns, we also suggest the use of mPHR as a diabetes care support tool enabling personalized management.

This study is unique when compared with previous studies on the basis of the following characteristics. First, we suggested the health improvement effect of mPHRs on the basis of the integration of PHRs and EMRs. In this study, we expected two benefits of integrating PHRs and EMRs. One is suggesting a different methodology for real-world data analysis and presenting additional real-world evidence, which supports previous studies. Another is ensuring a high-quality data analysis is conducted. There are many previous studies implying the advantages of PHRs and PGHD with positive conclusions of the use of mPHRs [14-17]. The results of these studies were collected on the basis of clinical trials such as nonblinded, open-label randomized controlled trials (RCTs) and cluster-randomized trial designs. As a real-world data analysis covers bias limitations in RCTs and can handle unknown factors 
of PHRs, the results of a real-world data analysis provide strong and necessary support to previous RCTs [25]. Moreover, the integration of EMRs gave high-quality $\mathrm{HbA}_{1 \mathrm{c}}$ data and diagnosis data, which made the analysis more precise.

Second, previous studies mainly discussed about the decrease in $\mathrm{HbA}_{1 \mathrm{c}}$ levels as an advantage of using PHRs. However, as the main goal of glycemic control is regulating a patient's $\mathrm{HbA}_{1 \mathrm{c}}$ level to the recommended range, we compared both $\mathrm{HbA}_{1 \mathrm{c}}$ decrease and proportions of patients who initially had a high $\mathrm{HbA}_{1 \mathrm{c}}$ level but their $\mathrm{HbA}_{1 \mathrm{c}}$ level decreased to a low value. According to the 2015 and 2019 diabetes management guidelines from the KDA, the recommended target $\mathrm{HbA}_{1 \mathrm{c}}$ level is $6.5 \%$ in patients with type 2 diabetes, and this differs from the guideline by the ADA $[4,26,27]$. As this study was conducted in AMC, South Korea, we used the guidelines from KDA and defined the cutoff value of the $\mathrm{HbA}_{1 \mathrm{c}}$ level as $6.5 \%$. Recent studies recommend that patients with severe diabetes mellitus should be controlled to lower than $7 \%$, depending on the severity and complications of diabetes [28-30]. Moreover, a stable decrease in blood glucose levels is also an important task in glycemic control. We also focused on the $r$-squared value of the trend line and SD as an indicator of stabilized $\mathrm{HbA}_{1 \mathrm{c}}$ decrease, but we could not achieve any outstanding results.

\section{Overall User Characteristics}

Analyzing users who had access to MCMH version 1.0 indicated that these users visited hospitals more with chronic diseases [21]. Continuous users were younger than noncontinuous users $(P<.001)$, and there was a significant difference in sex proportion; the continuous user group had a higher male ratio $(P<.001)$. In previous research, groups that used a PHR system had young users and a high proportion of males or generated more PGHD, especially those related to diabetes [21,22]. This is because male users aged between 51 and 70 years tend to adopt the PHR system [31]. In addition, in this study, the $\mathrm{HbA}_{1 \mathrm{c}}$ level in continuous users was measured for a shorter period $(P=.04)$ and more frequently $(P=.007)$ than noncontinuous users. However, the number of $\mathrm{HbA}_{1 \mathrm{c}}$ measurements had no significant difference between continuous and noncontinuous user groups. In South Korea, the social health insurance program was introduced with the 1977 National Health Insurance Act. This program was thereafter progressively rolled out to the general public, and it finally achieved universal coverage in 1989. According to the National Health Insurance Act, the criteria for the method, procedure, scope, and upper limit of health care shall be prescribed by the Ministry of Health and Welfare [17].

National insurance only supports up to $6 \mathrm{HbA}_{1 \mathrm{c}}$ tests per year, in accordance with the National Health Insurance Act. First, we considered the number of $\mathrm{HbA}_{1 \mathrm{c}}$ measurements as another indicator of diabetes severity. This is because well-controlled patients typically undergo $\mathrm{HbA}_{1 \mathrm{c}}$ tests twice a year, whereas poorly controlled individuals undergo testing 4 times a year [32]. However, the number of measurements seems to be similar because of the policy in South Korea. Although continuous users had shorter periods (approximately 80 days) between the first and last measurements, this group took $\mathrm{HbA}_{1 \mathrm{c}}$ tests more frequently. This may be because of the increase in hospital visits, along with more satisfaction and loyalty to the hospital [33]. To compare diabetes severity, the proportion of patients with an $\mathrm{HbA}_{1 \mathrm{c}}$ level of $6.5 \%$ or above, a first $\mathrm{HbA}_{1 \mathrm{c}}$ level measurement, and a DCSI score distribution were compared between continuous and noncontinuous groups. The two groups had no significant difference in the proportion of high $\mathrm{HbA}_{1 \mathrm{c}}$ levels and DCSI distribution; however, continuous users had a higher $\mathrm{HbA}_{1 \mathrm{c}}$ level $(P=.01)$. Retinopathy patients tended to use $\mathrm{MCMH}$ version 2.0 more continuously, but the complication proportion also had an insignificant difference between the two groups. Except for the first $\mathrm{HbA}_{1 \mathrm{c}}$ level measurement, most diabetic-related baseline characteristics appeared to have no significant difference, and the first $\mathrm{HbA}_{1 \mathrm{c}}$ measurement can be adjusted as confounders in an additional analysis. By using PHR and EMR integration, the general characteristics and severity of diabetes were compared.

As the period of $\mathrm{HbA}_{1 \mathrm{c}}$ measurement before $\mathrm{MCMH}$ version 2.0 use was shorter in the continuous group $(P<.001)$, continuous users seemed to have an earlier MCMH version 2.0 start compared with noncontinuous users. In addition, continuous users tended to use the sugar and diabetes calendar functions more and generate more data. This was because continuous users tended to use MCMH version 2.0 functions with fewer burdens.

\section{Verifying the Effect of Personal Health Record Use in Hemoglobin $A_{1 c}$ Control}

The main advantage of PHRs and PGHD is health improvement, especially in diabetes. Among the types of diabetes management, determining the change in $\mathrm{HbA}_{1 \mathrm{c}}$ levels was the most effective method to verify the effectiveness of PHRs in the real world. The results of this study indicate that continuous users had a larger decline; a greater increase in $\mathrm{HbA}_{1 \mathrm{c}}$ levels was observed in users who continuously used the diabetes management-related sugar function in MCMH version 2.0. As decline is the result of the trend line slope normalized to 100 days, the value itself also refers to the change in the $\mathrm{HbA}_{1 \mathrm{c}}$ level. For example, $\mathrm{HbA}_{1 \mathrm{c}}$ was $6.9 \%$ on January 1,2014 , and $\mathrm{HbA}_{1 \mathrm{c}}$ was $6.4 \%$ on October 19,2018 , in one particular continuous user; therefore, the decline value was -0.0044 , which means that this patient's change in $\mathrm{HbA}_{1 \mathrm{c}}$ level was approximately $-0.44 \%$ (100 times the value of decline). Thus, the decrease in $\mathrm{HbA}_{1 \mathrm{c}}$ levels in continuous users was approximately 1.9 times that in noncontinuous users. The result of ANCOVA shows that along with continuous use, other factors were also important: age, first $\mathrm{HbA}_{1 \mathrm{c}}$ measurement, DCSI, duration of using the sugar function, and $\mathrm{HbA}_{1 \mathrm{c}}$ measurement period before using $\mathrm{MCMH}$ version 2.0. Glycemic control is important for reducing both microvascular risk and emergent risk for myocardial infarction and death [34]. This indicates that the group that continuously used PHRs had health improvement with a decreasing trend of $\mathrm{HbA}_{1 \mathrm{c}}$ levels.

In glycemic control, it is important to reduce not only blood glucose levels but also hypoglycemic events [35]. Traditional diabetes care includes insulin delivery using syringes, pens, or pumps [3]. Although hypoglycemic side effects can occur with 
multiple daily injections and continuous subcutaneous insulin injection, the invasive characteristic of such forms of care is an inevitable disadvantage [36-39]. In this study, we tried to minimize the risk of hypoglycemic events in PHR-implemented diabetes management by using stability indicators, $r$-squared value and $S D$. However, stability was not ensured. In fact, a previous study showed increased glucose stability with the use of an internet-based glucose monitoring system [40]. This indicates that patients can improve hyperglycemia and hypoglycemia management by using PHRs with a blood glucose meter through continuous glucose monitoring diabetic care.

The goal of decreasing the $\mathrm{HbA}_{1 \mathrm{c}}$ level is to prevent the occurrence and aggravation of diabetic complications. Although the criterion for $\mathrm{HbA}_{1 \mathrm{c}}$ in a diagnostic test for diabetes has been recommended by the American Association of Clinical Endocrinologists and ADA, it is an "acceptable complementary diagnostic test for diabetes in Korean patients" [28,41]. Among the many glycemic controls, the tight regulation of $\mathrm{HbA}_{1 \mathrm{c}}$ levels is essential for health improvement and for lowering complication risks such as diabetic retinopathy [42]. In addition, the tight glycemic control of $\mathrm{HbA}_{1 \mathrm{c}}$ levels to $7.0 \%$ induces a lower risk of fracture in elderly patients with diabetes [43]. When comparing the ratio of patients with $\mathrm{HbA}_{1 \mathrm{c}}$ levels above and below $6.5 \%$ before and after the use of MCMH version 2.0, the group that continuously used MCMH version 2.0 had a higher proportion of regulated patients; initially, the first $\mathrm{HbA}_{1 \mathrm{c}}$ level measurement was over $6.5 \%$, and then it reduced to lower than $6.5 \%$. In addition, among users with the first $\mathrm{HbA}_{1 \mathrm{c}}$ level measurement over $6.5 \%$, the logistic regression results showed that regulation was associated not only with continuous use but also with age, first $\mathrm{HbA}_{1 \mathrm{c}}$ level measurement, and how fast MCMH version 2.0 was adapted. The data generation amount was thought to be important too, but it was statistically insignificant. Therefore, we can claim that the improvement of $\mathrm{HbA}_{1 \mathrm{c}}$ levels by PHR use can eventually affect diabetes management by controlling $\mathrm{HbA}_{1 \mathrm{c}}$ levels to $6.5 \%$ in practice.

\section{Limitations of This Research}

The main limitation of this study is the concern of general biases in real-world studies: selection bias, information bias, recall bias, and detection bias [44]. As this study mainly focused on analyzing real-world data, strict criteria and inevitable exclusion are necessary, leading to concerns in selection bias and detection bias. However, the criteria for the comparison group were the same, and despite including and excluding many patient criteria and comparing with the MCMH 1.0 user analysis, the study scale is almost similar [22]. The size of the continuous user groups is sometimes larger than that used in other RCT studies and had little baseline differences in diabetic severity [17]. As MCMH version 2.0 data are PGHD, continuous use can only be analyzed by its log data, which does not represent adherence to the app and can lead to information bias. On the contrary, we note that information bias that can occur in $\mathrm{HbA}_{1 \mathrm{c}}$ level scaling can be controlled with the integration of EMRs. This integration helped in reducing recall bias in diabetes and complication diagnosis.
Time scale is also another limitation. In RCTs, the $\mathrm{HbA}_{1 \mathrm{c}}$ measurement point, the app account creation point, and app use frequency can be controlled and optimized for convenient data analysis. However, in real-world data, patients have diverse points of $\mathrm{HbA}_{1 \mathrm{c}}$ measurement and $\mathrm{MCMH}$ version 2.0 starting points. Even though there were limitations with regard to missing data, inappropriate data, and ambiguous time scale standards, we used patient selection criteria to choose patients who can be analyzed and used the decline factor to monitor the $\mathrm{HbA}_{1 \mathrm{c}}$ level for minimizing the effect of irregular time points. The decline factor is a variable that has been coined for the purpose of this study and has an uncertain clinical rationale. However, as the decline variable also implies a decrease in $\mathrm{HbA}_{1 \mathrm{c}}$ levels, and the decreasing trend is being maintained, the quantitative comparison of decline between groups is meaningful. In diabetes care, lowering $\mathrm{HbA}_{1 \mathrm{c}}$ levels to the target level and maintaining the decreased $\mathrm{HbA}_{1 \mathrm{c}}$ level is the primary goal. Thus, the decline is a reasonable variable for analysis in studies with data having unspecific $\mathrm{HbA}_{1 \mathrm{c}}$ measurement points.

An additional limitation is that AMC is a territorial hospital, and almost all the study patients are residing in South Korea. The small size of the study population and short duration are other limitations. The low frequency of PHR data generation and short-term MCMH version 2.0 operation is not an ideal database for analyzing chronic diseases such as diabetes. A larger study size and longer study duration will provide stronger real-world evidence of the clinical meaning of PHRs.

On the basis of the proportion of continuous and noncontinuous users, further research for encouraging patients to use PHRs more continuously is essential. In this study, continuous users had better diabetes management outcomes than noncontinuous users. However, continuous users were only $1.78 \%$ (133/7453) of the study population and were only $0.20 \%(133 / 64,932)$ of users who started using MCMH version 2.0. Thus, studies for maintaining active PGHD-generating users and turning noncontinuous users into continuous users are necessary. Finding out whether giving health-related advice on the basis of MCMH version 2.0 encourages patients to use a PHR app for changing app use patterns needs to be studied to prevent usability issues [45]. Furthermore, for personalized PHR advice, if larger and better quality of data is provided, the glycemic control outcome analysis by treatment is important. Further studies in diverse territories and a deeper analysis of MCMH version 2.0 should be performed to prove the effectiveness of PHRs as a diabetes management tool in decreasing $\mathrm{HbA}_{1 \mathrm{c}}$ levels.

\section{Conclusions}

By integrating and analyzing patient- and clinically generated data, the continuous use of PHRs improves diabetes management outcomes. A greater decrease in $\mathrm{HbA}_{1 \mathrm{c}}$ levels was observed in continuous users, and $\mathrm{HbA}_{1 \mathrm{c}}$ levels were regulated to the target level in continuous users compared with noncontinuous users. Previous clinical trials and the results of this study proved that PHRs are effective in managing diabetes. However, further evaluation of the effectiveness of PHRs in various diseases and studies for adherence to PHRs are needed. A larger study 
population and longer duration will be necessary for the accurate analysis of the clinical rationale of PHRs on chronic diseases.

\section{Acknowledgments}

The authors would like to thank the Medical Information Office of AMC for providing log data of the mobile EMR and supporting data analysis and interpretation. This study was supported by a grant of the Research and Development Project, Ministry of Trade, Industry and Energy, Republic of Korea (no. 20004503) and a grant of the National Research Foundation of Korea funded by the Korean government (Ministry of Science and ICT; no NRF-2019M3E5D4064682).

\section{Authors' Contributions}

DS, YP, and JL conceived and designed the study; DS, YL, and JK reviewed records and collected the data; DS analyzed the data; DS and YP wrote the manuscript; and YP, JP, and JL reviewed the manuscript.

\section{Conflicts of Interest}

None declared.

\section{Multimedia Appendix 1}

Formula of decline.

[PNG File, 5 KB-Multimedia Appendix 1]

\section{Multimedia Appendix 2}

Diabetes complications severity index score proportion comparison of continuous and noncontinuous users.

[PNG File, 26 KB-Multimedia Appendix 2]

\section{References}

1. Shaw JE, Sicree RA, Zimmet PZ. Global estimates of the prevalence of diabetes for 2010 and 2030. Diabetes Res Clin Pract 2010 Jan;87(1):4-14. [doi: 10.1016/j.diabres.2009.10.007] [Medline: 19896746]

2. Wild S, Roglic G, Green A, Sicree R, King H. Global prevalence of diabetes: estimates for the year 2000 and projections for 2030. Diabetes Care 2004 May;27(5):1047-1053. [doi: 10.2337/diacare.27.5.1047] [Medline: 15111519$]$

3. American Diabetes Association. 7. Diabetes Technology: Standards of Medical Care in Diabetes-2019. Diabetes Care 2019 Jan;42(Suppl 1):S71-S80. [doi: 10.2337/dc19-S007] [Medline: 30559233]

4. Kim MK, Ko S, Kim B, Kang ES, Noh J, Kim S, Committee of Clinical Practice Guidelines, Korean Diabetes Association. 2019 clinical practice guidelines for type 2 diabetes mellitus in Korea. Diabetes Metab J 2019 Aug;43(4):398-406 [FREE Full text] [doi: 10.4093/dmj.2019.0137] [Medline: 31441247]

5. Riddle MC, Herman WH. The cost of diabetes care-an elephant in the room. Diabetes Care 2018 May;41(5):929-932. [doi: 10.2337/dci18-0012] [Medline: 29678864]

6. American Diabetes Association. Economic costs of diabetes in the US in 2017. Diabetes Care 2018 May;41(5):917-928 [FREE Full text] [doi: 10.2337/dci18-0007] [Medline: 29567642]

7. Rodríguez AQ, Wägner AM. Mobile phone applications for diabetes management: A systematic review. Endocrinol Diabetes Nutr 2019 May;66(5):330-337. [doi: 10.1016/j.endinu.2018.11.005] [Medline: 30745121]

8. Grady M, Katz LB, Cameron H, Levy BL. Diabetes app-related text messages from health care professionals in conjunction with a new wireless glucose meter with a color range indicator improves glycemic control in patients with type 1 and type 2 diabetes: randomized controlled trial. JMIR Diabetes 2017 Aug 7;2(2):e19 [FREE Full text] [doi: 10.2196/diabetes.7454] [Medline: 30291092]

9. Derdzinski M, Welsh J, Puhr S, Walker TC, Parker A, Jimenez A. 391-P: Hypoglycemia Reductions with the Dexcom G6 CGM System's Predictive Alert. Diabetes 2019 Jun;68(Supplement 1):391-P. [doi: 10.2337/db19-391-p]

10. Adolfsson P, Hartvig NV, Kaas A, NygÅRd NK, MÅRdby AC, Hellman J. 1076-P: Increased Time-in-Range (TIR) Observed after Introduction of a Connected Insulin Pen. Diabetes 2019;68(Supplement 1):1076-P. [doi: 10.2337/db19-1076-p]

11. Adolfsson P, Hartvig NV, Kaas A, Knudsen NN, MÅRdby A, MøLler JB, et al. 126-LB: Improved Insulin Adherence after Introduction of a Smart Connected Insulin Pen. Diabetes 2019 Jun;68(Supplement 1):126-LB. [doi: 10.2337/db19-126-lb]

12. Han M, Lee E. Effectiveness of mobile health application use to improve health behavior changes: a systematic review of randomized controlled trials. Healthc Inform Res 2018 Jul;24(3):207-226 [FREE Full text] [doi: 10.4258/hir.2018.24.3.207] [Medline: 30109154]

13. Yi JY, Kim Y, Cho Y, Kim H. Self-management of chronic conditions using mHealth interventions in Korea: a systematic review. Healthc Inform Res 2018 Jul;24(3):187-197 [FREE Full text] [doi: 10.4258/hir.2018.24.3.187] [Medline: 30109152] 
14. Quinn CC, Clough SS, Minor JM, Lender D, Okafor MC, Gruber-Baldini A. WellDoc mobile diabetes management randomized controlled trial: change in clinical and behavioral outcomes and patient and physician satisfaction. Diabetes Technol Ther 2008 Jun;10(3):160-168. [doi: 10.1089/dia.2008.0283] [Medline: 18473689]

15. Quinn CC, Shardell MD, Terrin ML, Barr EA, Ballew SH, Gruber-Baldini AL. Cluster-randomized trial of a mobile phone personalized behavioral intervention for blood glucose control. Diabetes Care 2011 Sep;34(9):1934-1942 [FREE Full text] [doi: 10.2337/dc11-0366] [Medline: 21788632]

16. Yu Y, Yan Q, Li H, Li H, Wang L, Wang H, et al. Effects of mobile phone application combined with or without self-monitoring of blood glucose on glycemic control in patients with diabetes: A randomized controlled trial. J Diabetes Investig 2019 Sep;10(5):1365-1371 [FREE Full text] [doi: 10.1111/jdi.13031] [Medline: 30815973]

17. Lee DY, Park J, Choi D, Ahn H, Park S, Park C. The effectiveness, reproducibility, and durability of tailored mobile coaching on diabetes management in policyholders: A randomized, controlled, open-label study. Sci Rep 2018 Feb 26;8(1):3642 [FREE Full text] [doi: 10.1038/s41598-018-22034-0] [Medline: 29483559]

18. Lester M, Boateng S, Studeny J, Coustasse A. Personal health records: beneficial or burdensome for patients and healthcare providers? Perspect Health Inf Manag 2016;13:1h [FREE Full text] [Medline: 27134613]

19. Showell C. Barriers to the use of personal health records by patients: a structured review. PeerJ 2017;5:e3268 [FREE Full text] [doi: $10.7717 /$ peerj.3268] [Medline: 28462058]

20. Tenforde M, Nowacki A, Jain A, Hickner J. The association between personal health record use and diabetes quality measures. J Gen Intern Med 2012 Apr;27(4):420-424 [FREE Full text] [doi: 10.1007/s11606-011-1889-0] [Medline: 22005937]

21. Lee G, Park JY, Shin S, Hwang JS, Ryu HJ, Lee JH, et al. Which users should be the focus of mobile personal health records? Analysis of user characteristics influencing usage of a tethered mobile personal health record. Telemed J E Health 2016 May;22(5):419-428 [FREE Full text] [doi: 10.1089/tmj.2015.0137] [Medline: 26447775]

22. Park YR, Lee Y, Kim JY, Kim J, Kim HR, Kim Y, et al. Managing patient-generated health data through mobile personal health records: analysis of usage data. JMIR Mhealth Uhealth 2018 Apr 9;6(4):e89 [FREE Full text] [doi: 10.2196/mhealth.9620] [Medline: 29631989]

23. Glasheen WP, Renda A, Dong Y. Diabetes Complications Severity Index (DCSI)-Update and ICD-10 translation. J Diabetes Complications 2017 Jun;31(6):1007-1013 [FREE Full text] [doi: 10.1016/j.jdiacomp.2017.02.018] [Medline: 28416120]

24. World Health Organization. Geneva: World Health Organization; 2011. Use of Glycated Haemoglobin (HbA1c) in the Diagnosis of Diabetes Mellitus: Abbreviated Report of a WHO Consultation URL: https://www.who.int/diabetes/publications/ report-hba1c 2011.pdf [accessed 2020-03-12]

25. Jadad AR, Enkin MW. Bias in randomized controlled trials. In: Jadad AR, Enkin MW, editors. Randomized Controlled Trials: Questions, Answers and Musings. Paris: BMJ Books; 2007:29-47.

26. Ha KH, Kim DJ. Current status of managing diabetes mellitus in Korea. Korean J Intern Med 2016 Sep;31(5):845-850 [FREE Full text] [doi: 10.3904/kjim.2016.253] [Medline: 27604796]

27. Fruh SM. Obesity: Risk factors, complications, and strategies for sustainable long-term weight management. J Am Assoc Nurse Pract 2017 Oct;29(S1):S3-14 [FREE Full text] [doi: 10.1002/2327-6924.12510] [Medline: 29024553]

28. Handelsman Y, Bloomgarden ZT, Grunberger G, Umpierrez G, Zimmerman RS, Bailey TS, et al. American association of clinical endocrinologists and american college of endocrinology - clinical practice guidelines for developing a diabetes mellitus comprehensive care plan - 2015. Endocr Pract 2015 Apr;21(Suppl 1):1-87 [FREE Full text] [doi: 10.4158/EP15672.GL] [Medline: 25869408]

29. American Diabetes Association. 6. Glycemic Targets. Diabetes Care 2017;40(Supplement 1):S48-S56. [doi: $\underline{10.2337 / \mathrm{dc} 17-\mathrm{s} 009]}$

30. Qaseem A, Wilt TJ, Kansagara D, Horwitch C, Barry MJ, Forciea MA, Clinical Guidelines Committee of the American College of Physicians. Hemoglobin A1c targets for glycemic control with pharmacologic therapy for nonpregnant adults with type 2 diabetes mellitus: a guidance statement update from The American College of Physicians. Ann Intern Med 2018 Apr 17;168(8):569-576. [doi: 10.7326/M17-0939] [Medline: 29507945]

31. Nazi KM. Veterans' voices: use of the American Customer Satisfaction Index (ACSI) Survey to identify My HealtheVet personal health record users' characteristics, needs, and preferences. J Am Med Inform Assoc 2010;17(2):203-211 [FREE Full text] [doi: 10.1136/jamia.2009.000240] [Medline: 20190065]

32. Canadian Agency for Drugs and Technologies in Health. 2014. HbA1c Testing Frequency: A Review of the Clinical Evidence and Guidelines URL: https://www.cadth.ca/hba1c-testing-frequency-review-clinical-evidence-and-guidelines [accessed 2020-03-12]

33. Cho WH, Lee H, Kim C, Lee S, Choi K. The impact of visit frequency on the relationship between service quality and outpatient satisfaction: a South Korean study. Health Serv Res 2004 Feb;39(1):13-33 [FREE Full text] [doi: 10.1111/j.1475-6773.2004.00213.x] [Medline: 14965075]

34. Holman RR, Paul SK, Bethel MA, Matthews DR, Neil HA. 10-year follow-up of intensive glucose control in type 2 diabetes. N Engl J Med 2008 Oct 9;359(15):1577-1589. [doi: 10.1056/NEJMoa0806470] [Medline: 18784090]

35. Amiel SA, Sherwin RS, Simonson DC, Tamborlane WV. Effect of intensive insulin therapy on glycemic thresholds for counterregulatory hormone release. Diabetes 1988 Jul;37(7):901-907. [doi: 10.2337/diab.37.7.901] [Medline: 3290007] 
36. Wong JC, Dolan LM, Yang TT, Hood KK. Insulin pump use and glycemic control in adolescents with type 1 diabetes: Predictors of change in method of insulin delivery across two years. Pediatr Diabetes 2015 Dec;16(8):592-599 [FREE Full text] [doi: 10.1111/pedi.12221] [Medline: 25387433]

37. Wheeler BJ, Heels K, Donaghue KC, Reith DM, Ambler GR. Insulin pump-associated adverse events in children and adolescents--a prospective study. Diabetes Technol Ther 2014 Sep;16(9):558-562. [doi: 10.1089/dia.2013.0388] [Medline: 24796368]

38. Kordonouri O, Biester T, Schnell K, Hartmann R, Tsioli C, Fath M, et al. Lipoatrophy in children with type 1 diabetes: an increasing incidence? J Diabetes Sci Technol 2015 Mar;9(2):206-208 [FREE Full text] [doi: 10.1177/1932296814558348] [Medline: 25411060]

39. Yeh H, Brown TT, Maruthur N, Ranasinghe P, Berger Z, Suh YD, et al. Comparative effectiveness and safety of methods of insulin delivery and glucose monitoring for diabetes mellitus: a systematic review and meta-analysis. Ann Intern Med 2012 Sep 4;157(5):336-347. [doi: 10.7326/0003-4819-157-5-201209040-00508] [Medline: 22777524]

40. Cho J, Chang S, Kwon H, Choi Y, Ko S, Moon S, et al. Long-term effect of the internet-based glucose monitoring system on HbA1c reduction and glucose stability: a 30-month follow-up study for diabetes management with a ubiquitous medical care system. Diabetes Care 2006 Dec;29(12):2625-2631. [doi: 10.2337/dc05-2371] [Medline: 17130195]

41. Jeon JY, Ko S, Kwon H, Kim NH, Kim JH, Kim CS, Taskforce Team of Diabetes Fact Sheet of the Korean Diabetes Association. Prevalence of Diabetes and Prediabetes according to Fasting Plasma Glucose and HbA1c. Diabetes Metab J 2013 Oct;37(5):349-357 [FREE Full text] [doi: 10.4093/dmj.2013.37.5.349] [Medline: 24199164]

42. Rajalakshmi R, Prathiba V, Mohan V. Does tight control of systemic factors help in the management of diabetic retinopathy? Indian J Ophthalmol 2016 Jan;64(1):62-68 [FREE Full text] [doi: 10.4103/0301-4738.178146] [Medline: 26953026]

43. Conway BN, Long DM, Figaro MK, May ME. Glycemic control and fracture risk in elderly patients with diabetes. Diabetes Res Clin Pract 2016 May;115:47-53 [FREE Full text] [doi: 10.1016/j.diabres.2016.03.009] [Medline: 27242122]

44. Blonde L, Khunti K, Harris SB, Meizinger C, Skolnik NS. Interpretation and impact of real-world clinical data for the practicing clinician. Adv Ther 2018 Nov;35(11):1763-1774 [FREE Full text] [doi: 10.1007/s12325-018-0805-y] [Medline: 30357570]

45. Jeon E, Park H. Development of the IMB model and an evidence-based diabetes self-management mobile application. Healthc Inform Res 2018 Apr;24(2):125-138 [FREE Full text] [doi: 10.4258/hir.2018.24.2.125] [Medline: 29770246]

\author{
Abbreviations \\ ADA: American Diabetes Association \\ AMC: Asan Medical Center \\ ANCOVA: analysis of covariance \\ DCSI: diabetes complications severity index \\ EMR: electronic medical record \\ HbA $_{1 \mathbf{c}}$ : hemoglobin $\mathrm{A}_{1 \mathrm{c}}$ \\ ICD-10: International Classification of Diseases 10th Revision \\ IRB: institutional review board \\ KDA: Korean Diabetes Association \\ MCMH: My Chart in My Hand \\ mHealth: mobile health \\ MPHR: mobile personal health record \\ PGHD: patient-generated health data \\ PHR: personal health record \\ RCT: randomized controlled trial
}

Edited by G Eysenbach; submitted 05.07.19; peer-reviewed by SY Jung, L Luo, S Ross; comments to author 16.12.19; revised version
received 10.02.20; accepted 24.02.20; published 02.06 .20
Please cite as:
Seo D, Park YR, Lee Y, Kim JY, Park JY, Lee JH
The Use of Mobile Personal Health Records for Hemoglobin A1c Regulation in Patients With Diabetes: Retrospective Observational
Study
J Med Internet Res 2020;22(6):e15372
URL: $\underline{\text { https://www.jmir.org/2020/6/e15372 }}$
doi: $\underline{10.2196 / 15372}$
PMID: $\underline{32484447}$


CDongjin Seo, Yu Rang Park, Yura Lee, Ji Young Kim, Joong-Yeol Park, Jae-Ho Lee. Originally published in the Journal of Medical Internet Research (http://www.jmir.org), 02.06.2020. This is an open-access article distributed under the terms of the Creative Commons Attribution License (https://creativecommons.org/licenses/by/4.0/), which permits unrestricted use, distribution, and reproduction in any medium, provided the original work, first published in the Journal of Medical Internet Research, is properly cited. The complete bibliographic information, a link to the original publication on http://www.jmir.org/, as well as this copyright and license information must be included. 